\title{
Looking at cirrus clouds
}

\section{Munich}

A UNIQUE high-altitude aeroplane will take off in West Germany on 17 September as part of a European airborne team that will investigate cirrus clouds and their effects on the climate. The clouds, which are made up of ice needles and play an important but little investigated role in

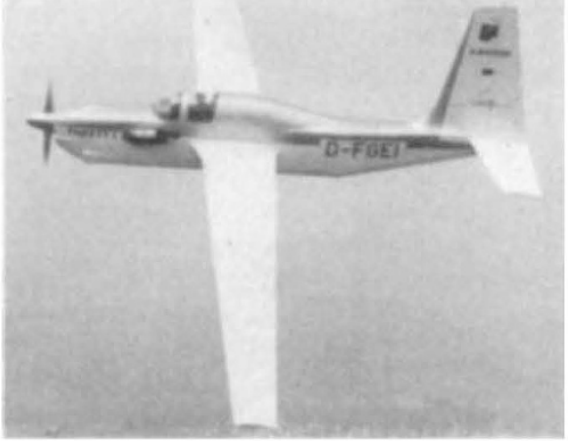

Stratolab will look at Cirrus clouds.

global warming, will be studied in detail by the project, called the International Cirrus Experiment (ICE).

ICE, which is funded by four European governments - West Germany, Britain, France and Sweden - as well as the European Communities Commission, will involve simultaneous, parallel flights by up to five aeroplanes above, within and below the cirrus clouds $10 \mathrm{~km}$ above the North Sea. Equipment on the planes and on ships below will monitor the relationship between the ice crystals that make up the clouds and the clouds' ability to transmit heat or light. ICE is also expected to deliver important data on the physical properties of the crystals themselves, including their density and structure.

West German project leader Ehrhard Raschke of the University of Cologne says that ICE will complement the data about cirrus clouds obtained by the US-backed FIRE project (First International Radiation Experiment) of 1986. More aircraft will be used for ICE than for FIRE.

In order to maintain a stable climate, the Earth must return most of the Sun's radiation to space. Like other clouds, cirrus clouds allow sunlight to pass through, and when the same energy is reradiated from the Earth's surface in the form of heat, they reflect it back to Earth. Because of the sparsity of measurements on cirrus clouds, they have remained something of an unknown quantity, but they are thought to play a potentially significant role in the greenhouse effect. The planes will fly up to three times a week for up to five weeks, although Raschke says he will be happy if six successful flights are made. The North Sea was chosen both because the researchers could obtain the necessary clearance from military and civilian authorities to fly and because it provides a homogeneous background against which to measure heat transfer. Project leaders also believe that the chances are good of finding cirrus there.

The high-flying plane, called Stratolab, is the first turboprop to reach altitudes of 53,000 feet $(16 \mathrm{~km})$. Originally called Egret, it is the product of a collaboration between the West German sailplane manufacturer Grob-Werke $\mathrm{GmbH}$, the Texas-based electronics company E-Systems, and the private WIB-Berlin Space Institute. Stratolab was built to fly above 90 per cent of the atmosphere, into the middle of the protective stratosphere ozone layer there. It is the only European research plane that can fly so high.

Stratolab is effectively a sailplane equipped with an engine. At high altitudes, the plane can glide 40 to 45 metres for every metre of altitude lost. The propeller functions in the thin air at only 10 per cent efficiency, so gliding is a necessity. The plane could in theory carry two people, a pilot and a scientist, but in ICE there will

\section{University reopens}

London

THE 'Vytautas the Great' University of Kaunas is to reopen on 1 September, after a gap of nearly 40 years, in response to a public campaign in Lithuania.

The university was founded in 1922, at a time when Kaunas was the capital of the newly independent state of Lithuania. The university was closed down in the Second World War during the Nazi occupation, and briefly reopened under Soviet rule, but was then suppressed in 1950 as part of Stalin's clampdown in the Baltic republics. Although the university was replaced by a medical school and a polytechnic institute, the closure effectively deprived Kaunas of university-level education in the humanities and the natural sciences.

Vera Rich

be no passenger because the cabin is not pressurized. The pilot has to wear a specially fitted space suit. The Berlin institute, run by West German astronaut Reinhard Furrer, is currently working on equipment to measure stratospheric ozone and other trace gases using the plane.
Steven Dickman

\section{ACID RAIN}

\section{China blamed for high pH}

\section{Tokyo}

JAPAN is suffering from acid rain and China may be one of the sources, according to the results of a five-year nationwide survey released recently by the Environment Agency.

The first suspicions of acid-rain pollution in Japan emerged more than three years ago when researchers reported low $\mathrm{pH}$ levels in rain water and some damage to trees (see Nature 319, 711; 1986). The agency survey at 29 locations around the country shows that acid rain (defined as rain water with a $\mathrm{pH}$ of less than 5.6) is falling throughout the country. But the average level of acidity at the 29 locations ( $\mathrm{pH}$ of $4.4-5.5)$ is not as severe as in Europe and North America (average levels about $\mathrm{pH} 4.0$ ). And the agency has not found any conclusive evidence of damage to trees, lakes or soil by acid rain. But it fears that damage may result even at these levels over the long term.

Japan implemented strict measures to combat air pollution in the early 1970 s and as a result, emissions of sulphur and nitrogen oxides that cause acid rain have been kept down. But there is growing evidence that the continental mainland, in particular China, may be a source of airborne pollution, and with the rapid industrialization of China the problem is likely to get worse.

In 1986, the Environment Agency reported rising levels of a pesticide (benzene hexachloride) that is not used in Japan in a lake in the northern island of Hokkaido. And the agency suspects that the pesticide, which is used in China and Korea, may have been blown over from the continent (see Nature 320, 478; 1986). Later the same year, the Shimane Prefecture Sanitation and Pollution Research Institute which faces the Japan Sea reported that strongly acidic rain (with $\mathrm{pH}$ as low as 3.1) frequently falls in the area. As there are no factories nearby, the continental mainland, in particular China, is again suspected. And the results of the present survey show that levels of sulphur and nitrogen oxides in acid rain on the Japan Sea coast increase in winter when prevailing winds blow from the continent.

China suffers from severe acid rain problems and during a recent visit to China by Japan's former prime minister Noboru Takeshita, Japan, at China's request, allocated $¥ 10,000$ million $(\$ 70$ million) in overseas development aid to build an environmental institute in Beijing that will have pollution monitoring stations around the country. The institute will carry out research and train state and municipal officials to deal with pollution problems. But as a result of the Tiananmen Square massacre, the project has been temporarily suspended. Hisakazu Kato of the Environment Agency, however, expects that the project will pick up again in "the very near future". David Swinbanks 